\title{
Dental Technicians: Unsung Heroes of Dentistry
}

\author{
Pravinkumar G Patil \\ International Journal of Prosthodontics and Restorative Dentistry (2020): 10.5005/jp-journals-10019-1266
}

Dental technology is one of the vital components of a team of the dental professionals. It is the art, science, and technologies that enable the design and fabrication of dental prostheses and/ or corrective devices to restore natural teeth and supporting structures to fulfill a patient's physiological and esthetic needs. ${ }^{1}$ A collaborative relationship between dentists and dental technicians can greatly improve the esthetic and functional results of prosthetic restorations. ${ }^{2}$ Curtis et al. ${ }^{3}$ have done a qualitative study on the roles and relationships of registered clinical dental technicians (CDTs) in the dental team as a professional group in the United Kingdom (UK). Though technicians expressed pride, passion, and satisfaction in their work, they still feel that their inter-professional relations must be addressed appropriately to enhance overall patient care.

Dental technicians mostly are working in an unfavorable work environment as frequent drilling and trimming procedures during prosthesis fabrication create noise and dust leading to develop the occupational health hazards. There are cases being reported on developing pneumoconiosis as a result of exposure to dust in different parts of the world. Alici et al. ${ }^{4}$ evaluated a total of 70 dental technicians referred with the suspicion of occupational disease and almost 46 (65.7\%) of them were diagnosed with pneumoconiosis in one of the reference centers in Turkey. Al-Omoush et al. ${ }^{5}$ examined 244 dentists, dental technicians, assistants, and students for hearing impairment and observed that the impairment is higher among dental assistants and technicians than that of the control group. Dental technicians are also exposed to transmission of the infection from dental clinics through impressions. Al Mortadi et al. ${ }^{6}$ studied practices of disinfection of dental impressions in Jordan with a total of 85 dental technicians through self-administered questionnaire. They found out that majority of the laboratories did not have instructions related to the disinfection of impressions and about $44 \%$ laboratories never disinfect impressions. Despite hardships of dental technicians and their compromised work environment, many of them are living up to the high expectations of dentists as well as patients.

The dental technicians, according to me, are the artists who put so much efforts in designing and creating the esthetic prosthetic restorations. Different types of prostheses including all-ceramic/ metal-ceramic crowns/bridges, implant-supported prostheses, removable partial or complete dentures, and laminate-veneers require dedicated technicians to work at their highest artistic abilities. Yet, as per the best of my knowledge, maximum of them are far away from grabbing recognition or ownership of their "artwork" (a fixed or removable prosthesis in this context). Moreover, when it
Department of Prosthodontics, Division of Clinical Dentistry, School of Dentistry, International Medical University, Kuala Lumpur, Malaysia

Corresponding Author: Pravinkumar G Patil, Department of Prosthodontics, Division of Clinical Dentistry, School of Dentistry, International Medical University, Kuala Lumpur, Malaysia, Phone: +60 1135022042, e-mail: pravinandsmita@yahoo.co.in

How to cite this article: Patil PG. Dental Technicians: Unsung Heroes of Dentistry. Int J Prosthodont Restor Dent 2020;10(1):2.

Source of support: Nil

Conflict of interest: None

comes to publishing post-treatment clinical photographs with final prostheses in the scientific journals or dental magazines, one can hardly notice appropriate credit being given to the technicians who work hand in hand with the dentists. Mostly, only dentists who treat cases receive appropriate recognition by providing authorships or by indicating their names with clinical photographs in scientific journals or dental magazines. There should be some guidelines, for publishing clinical photographs with prosthetic restorations, in providing appropriate recognition or credit to the technician/s or to the dental laboratory involved.

\section{References}

1. Bobich AM, Mitchell BL. Transforming dental technology education: skills, knowledge, and curricular reform. J Dent Educ 2017;81(9):eS59eS64. DOI: 10.21815/JDE.017.035.

2. Pietrobon N, Malament KA. Team approach between prosthodontics and dental technology. Eur J Esthet Dent 2007;2(1):58-79.

3. Curtis S, Gurveer J, Gallagher JE. Clinical dental technicians in the United Kingdom: a qualitative understanding of the experiences, of practices and challenges of communication for dental professionals. Gerodontology 2019;36(4):405-416. DOI: 10.1111/ger.12413.

4. Alici NŞ, Beyan AC, DemıralY, etal. Dental technicians' pneumoconiosis; illness behind a healthy smile - case series of a reference center in Turkey. Indian J Occup Environ Med 2018;22(1):35-39. DOI: 10.4103/ ijoem.IJOEM_41_18.

5. Al-Omoush SA, Abdul-Baqi KJ, Zuriekat M, et al. Assessment of occupational noise-related hearing impairment among dental health personnel. J Occup Health 2019;62(1):e12093. DOI: 10.1002/13489585.12093.

6. Al Mortadi N, Al-Khatib A, Alzoubi KH, et al. Disinfection of dental impressions: knowledge and practice among dental technicians. Clin Cosmet Investig Dent 2019;11:103-108. DOI: 10.2147/CCIDE. S205144.

(0) The Author(s). 2020 Open Access This article is distributed under the terms of the Creative Commons Attribution 4.0 International License (https://creativecommons. org/licenses/by-nc/4.0/), which permits unrestricted use, distribution, and non-commercial reproduction in any medium, provided you give appropriate credit to the original author(s) and the source, provide a link to the Creative Commons license, and indicate if changes were made. The Creative Commons Public Domain Dedication waiver (http://creativecommons.org/publicdomain/zero/1.0/) applies to the data made available in this article, unless otherwise stated. 